\title{
The Eye's Mind: Perceptual Process and Epistemic Norms
}

\author{
Jessie Munton
}

\begin{abstract}
Philosophers have tended to formulate theories of perceptual justification independently of psychological investigation into perceptual functioning. Nevertheless, work in perceptual epistemology often conceals an implicit commitment to a normative view of what kinds of processing maximise the epistemic power of a perceptual experience, that is, its capacity to justify belief. This implicit commitment is to a set of "minimalist" norms, which treat sensory stimulation as the ultimate locus of epistemic power, and consequently set value on the purity of sensory signal and passivity of perceptual processing. These norms fit poorly with our best scientific models of perception, which draw out the ways in which it can be understood as akin to a hypothesis. Focusing on visual perception in particular, I argue that appreciating how it plays the role of a hypothesis within the visual system, whilst also constituting a form of evidence at the person level, gives us reason to reject these minimalist norms for perceptual processing. ${ }^{1}$
\end{abstract}

\section{Introduction}

Visual experience can justify belief. Visual experience is also the result of a set of psychological processes. What is the significance of the latter set of facts for the former capacity? What role do psychological processes play in determining the epistemic value, or power, of a perceptual experience?2

According to one, influential train of thought in philosophy, the answer is, superficially at least, "none". For the most part, epistemic norms have been formulated in isolation from psychological inquiry into perception. Philosophers have often granted perceptual experience an exceptional epistemic role: it puts us in immediate contact with the world around us, and can provide a foundational level of justification for certain basic beliefs, on which we can ground, via inference, a web of more complex beliefs. On this picture, it can seem as though its epistemic power or value

\footnotetext{
${ }^{1} \mathrm{I}$ am indebted to Jason Stanley, Susanna Siegel, Daniel Greco and Hedda Hassel Mørch for detailed comments on earlier versions of the material in this paper. The paper has additionally benefited from feedback from audiences at the 2016 NEH Summer Institute on Presupposition and Perception, and in an earlier version from presentation at a workshop on the Epistemology of Cognitive Penetration at Harvard University.

2 Siegel (2017) coins the helpful term 'epistemic power' to describe the varying capacity of a mental state to offer justification to further states based upon it. I am interested in particular in variation in degree or strength of justification a perceptual experience can offer belief.
} 
(that is, the degree of justification a visual experience is capable of conferring on belief and its capacity to ground further inference) does not depend on psychological facts. After all, the contact it allows with the external world is characterized by its apparent immediacy, implying the absence of any epistemically relevant intermediate steps.

In the first part of this paper, I argue that, contrary to initial appearances, this approach is often implicitly committed to a substantive view of the appropriate role of psychological processing in visual perception. This view tends to identify the source of epistemic power in visual experience with raw sensory stimulation, or retinal data: as close as possible to the subject's sensory interface with the world. Doing so naturally implies a set of minimalist norms for visual processing, on which less is more, norms which preserve the "purity" of the sensory signal.

In the second part of the paper I show that those minimalist norms rest on an incomplete understanding of what visual experience is. Minimalist norms mesh naturally with a view on which visual experience is understood as a form of evidence received by the sensory receptors directly from the world. This is partly right: the phenomenal visual experience can be understood as a kind of evidence at the level of the individual, but the sensory signal itself is not evidence for the individual. ${ }^{3}$ Our best empirical models of perception have long encouraged us to understand it as a process of formulating bypotheses about the external world. On these models, incoming sensory signal is merely part of the input to a complex process that synthesizes it with background information of some form to arrive at a best guess about the distal environment, presented in the form of a phenomenal visual experience. The visual experience which constitutes our evidence at the person-level is identical not with the sensory signal itself, but with the hypothesis that is itself a dynamic response to the sensory signal.

After outlining this approach to visual perception in section two, in section three I draw out the inconsistency between it, and minimalist norms for perceptual processing. A hypothesis is underdetermined by the data it most immediately responds to. Whilst evidence may be passively received and transmitted, a hypothesis, by contrast, is the result of an active process of integrating stored and incoming information. This has important upshots for the norms we apply to perceptual processing. Sensory signal must be processed, evaluated, and sometimes discarded in the process of producing the person-level experience. We should not regard sensory signal then as evidence, in any

\footnotetext{
${ }^{3}$ I use "evidence" here to mean, simply, something to which a rational believer should be responsive when forming her beliefs. The nature of evidence is contested along various dimensions (Kelly, 2008), and I wish to remain neutral as far as possible on many of these debates. It is sometimes doubted that perception could constitute a form of evidence, on the grounds that our relationship with it is more direct than an evidential relation can adequately capture (Austin 1962, Lyons 2016a). since I understand evidence in such minimal terms, my willingness to describe perceptual experience as a form of evidence has no interesting bearing on the immediacy of the perceptual relationship. Similarly, I do not take a stand here on whether evidence must be propositional (Williamson 2000). I use 'data' to indicate a body of information which may or may not have the normative status of evidence.
} 
normatively laden sense, for the individual. That licenses more liberal epistemic norms for perceptual processing.

\section{Passivity, proximity and purity}

For the most part, epistemic norms for perception have been formulated independently of psychological investigation into the operation of the visual system. In fact, certain traditions of thought in perceptual epistemology positively imply that the epistemic power of visual experience is attributable to the irrelevance of psychological facts. Perceptual experience is epistemically special, runs one such influential train of thought, because it can provide a source of immediate, foundational, regress-stopping justification for our beliefs. Perception is the immediate interface between the mind and the world, the point at which our beliefs are most directly informed by our environment. We are justified in taking our experience at face value not because we have antecedent reason to do so, or because of certain psychological facts which legitimate the experiences in question, but simply in virtue of having the relevant perceptual experience.

The view James Pryor terms "dogmatism" is an instance of this kind of foundationalist approach. Pryor writes that

The dogmatist about perceptual justification says that when it perceptually seems to you as if $p$ is the case, you have a kind of justification for believing $p$ that does not presuppose or rest on your justification for anything else, which could be cited in an argument ... for $p$. To have this justification for believing $p$, you need only have an experience that represents $p$ as being the case. (2000: 519) 4

On this approach, just the fact that things seem a particular way to you justifies the belief that they are that way. We need not interrogate the seeming and its credentials before assigning it an epistemic status. The justification in question may be defeated, but prima facie perceptual justification arises simply from the fact that things seem, perceptually speaking, a certain way to you. When a belief is inferentially justified by another belief, one may enquire into its history in a way that can moderate the degree of justification the belief ultimately enjoys. But prima facie perceptual justification does not admit of further dissection of this kind.

In fact, this purported disavowal of the relevance of psychological fact to epistemic appraisal itself frequently amounts to a substantive position on the form that perceptual processing can legitimately take. Visual experience is often taken to get its foundational epistemic status from the way in which it

\footnotetext{
${ }^{4}$ Dogmatism here constitutes a claim about perceptual justification in particular. Dogmatism is an instance of a broader family of "Phenomenal Conservative" approaches. Phenomenal conservatism claims that we are justified in taking "seemings" in general, including doxastic seemings, at face value. Huemer describes the view thus: "If it seems to $S$ as if $P$, then $S$ thereby has at least prima facie justification for believing that $P$ " (2001:99). See Pryor (2005), Huemer (2007) for further developments of the position.
} 
puts us in direct contact with the environment, such that we gain information immediately and passively from the world. That emphasis on its immediacy and passivity gives rise to a psychological picture on which sense perception is a process not of interpreting or calculating or inferring, but of simply opening up to the world around us. That in turn implies a particular set of epistemic norms for perceptual processing. In this section, I describe three particularly prominent norms, of Passivity, Purity, and Proximity, and their relevant implications.

Ernest Sosa sets out the way in which the passivity imputed to visual experience purportedly allows it to play a distinctive epistemic role, in the course of describing what he calls the traditional perceptual model of knowledge, (a model which he goes on to reject).

Experiences are able to provide justification that is foundational because they lie beyond justification and unjustification. Since they are passively received, they cannot manifest obedience to anything, including rational norms, whether epistemic or otherwise. Since unmotivated by reasons, they can serve as foundational sources, as regress-stoppers. When they help explain the rational standing of some other state or action, they do not thereby problematize their own rational standing. Being so passive, they have no such standing. (2007: 46)

On the face of it, it can look as though this traditional model hinges on a claim that is primarily descriptive: that visual experience is passive, and foundational, an inappropriate site for rational evaluation. But that descriptive claim goes hand in hand with a normative one: that the epistemic power of visual experiences flows from their passivity. The traditional model accords perceptual experience a particular epistemic capacity, to provide foundational justification, in virtue of a psychological feature, namely, its passivity. The implication is that, were visual experience subject to some kind of more active processing, it would not enjoy the same privileged epistemic status.

I shall describe this as a norm of passivity:

PASSIVITY: visual experiences have a foundational epistemic status in virtue of being passively received from the environment.

The passivity norm represents a loose way of thinking about visual experience, not a precise demand. It leaves open the exact nature of passivity, and the extent of its relationship with epistemic power. But it represents an important strand in a broader web of related psychological norms concerning the relationship between epistemic justification and psychological process. 
Passivity has two particularly relevant implications. The first is this: an emphasis on the passivity of perceptual process has encouraged philosophers to think of the input to the perceptual system as itself of evidential value for the individual. After all, if perceptual processing is construed as passive, but perceptual experience is uniquely epistemically valuable, it must be that sensory input itself which provides, ready-made, that distinctive epistemic value. If perceptual processing is passive, there is nothing that could "add value" between the sensory signal and the individual.

\section{PASSIVITy IMPLiCATION \#1}

Evidential value: the information received at the sensory receptors is of evidential value for the individual. 5

Evidential value goes hand in hand with another psychological implication, that the function of perceptual processing is the mere transmission of information from sensory receptor to experiential subject. Since the sensory signal is evidentially valuable, since perception is essentially passive, the proper role of perceptual processing is just to transmit that valuable sensory signal to the individual.

\section{Passivity Implication \#2}

Function: the proper function of perceptual processing is the mere transmission of information from the sensory receptor.

Of course, few would want to deny a role for sensory transduction, the necessary transformation of signal at certain stages to allow for its presentation in conscious experience, but Function denies a place for more active processes of interpretation or transformation in the light, for instance, of additional, stored information.

Putting these together supports a further normative claim about the relationship between perceptual processing and epistemic power. Treating incoming sensory signal as an epistemic good, which is best conveyed passively and sans intervention by the visual system implies a hierarchy of epistemic power, tied to proximity to the sense receptor.

\footnotetext{
${ }^{5}$ Interestingly, past discussion of the inferential nature of perceptual experience has sometimes itself contributed to the view that sensory signals are epistemically valuable to the individual. By ascribing the relevant inferences to the person-level perceiver, it is implied that the retinal data which features in those inferences is evidence at the person-level. Harman (1973) includes some clear instances of this. He writes that "different sorts of stimulation of his retinal nerve represent different things to the perceiver" (1973:186), and asks whether 'he' believes the data. This implies that the retinal nerve stimulation has a form that an individual perceiver could believe. See too Helmholtz's 1867 account of perceptual inference which he envisages taking phenomenal sensations as input.
} 
Take Quine's case for a naturalized approach to epistemology. Quine urges that "[ $\mathrm{t}] \mathrm{he}$ stimulation of his sensory receptors is all the evidence anybody has had to go on, ultimately, in arriving at his picture of the world" (1969:75). Quine is implicitly endorsing the evidence claim above: sensory signals are of realised, epistemic value. Doing so naturally leads him to endorse a hierarchy of epistemic value, determined by proximity to that sensory stimulation. ${ }^{6}$

In the old anti-psychologistic days the question of epistemological priority was moot. What is epistemologically prior to what? Are Gestalten prior to sensory atoms...?

Now that we are permitted to appeal to physical stimulation, the problem dissolves; $A$ is epistemologically prior to B if A is causally nearer than B to the sensory receptors. Or, what is in some ways better, just talk explicitly in terms of causal proximity to sensory receptors and stop the talk of epistemological priority. (1969: 84-85)

I shall call this norm Proximity.

PROXIMITY: proximity to sensory reception establishes epistemic priority

If we think of sensory stimulation as providing a core of epistemic value, then it is natural to think that proximity to that core determines a hierarchy of epistemic status. On this way of thinking, the value of visual evidence, that is, the strength of justification it provides for belief, is highest when it reflects that sensory stimulation with as little interference as possible, beyond whatever minimal transduction is required to arrive at a visual experience. The proximity and passivity norms thereby naturally give rise to another implicit norm of psychological processing, a purity norm.

Take, for example, Dretske's claim that

...if one systematically strips away from a given perceptual act all the accretions due to past experience, all the collateral information, anticipations, interpretive and inferential elements, all the habitual or conditional associations, then one will be left with a "pure sensory core" - the given of sense experience. (1969:75)

\footnotetext{
${ }^{6}$ Interestingly, at other moments in the same work Quine endorses a principle of broad engagement with available information, given the impossibility of deducing science from observations alone, in a manner that accords well with the normative approach towards perceptual processing I endorse below. He writes that "scruples against circularity have little point once we have stopped dreaming of deducing science from observations. If we are out simply to understand the link between observation and science, we are well advised to use any available information, including that provided by the very science whose link with observation we are seeking to understand" (1969:76).
} 
That sensory core, cleansed of unnecessary accretions is as close as experience can come to pure, sensory stimulation. In his (1969), Dretske ultimately disagrees with that particular conception of the sensory core, though not with the notion of a sensory core per se. ${ }^{7}$ Dretske echoes a tradition that emphasizes the epistemic centrality of some level of experience, often identified as sensation, that directly reflects the impingement of the world on our senses. Russell, half a century earlier, writes that "to arrive at what really is sensation... we have to pare away all that is due to habit or expectation or interpretation" (Russell 1921:178). "Sensations”, writes Russell “are obviously the source of our knowledge of the world, including our own body,” (1921:179) and for Russell “... the essence of sensation is its independence of past experience” (Russell 1921:183).

Dretske refers to the sensory core as "pure". On the one hand, that emphasis on purity can look like a rejection of the possibility of evaluating psychological processes that give rise to visual experience. But that impression is misleading: purity itself is a norm of psychological processing: that there should be as little as possible, that sensory stimulation should not be occluded by or infected with extra-sensory information. This approach again links the epistemic features of visual experience with certain psychological characteristics. Sensation, or the sensory core, is pure of accretion, and epistemically powerful for that.

PURITY: visual perception is epistemically powerful in virtue of its independence from extra-sensory influence.

Purity suggests that visual experience is maximally powerful when it reflects occurrent sensory stimulation with as little interpolation of additional information as possible. And this is certainly a natural thought: if perception is in the business of putting us in contact with our immediate environment, in such a way that it allows us to form accurate beliefs and to act effectively in that environment, it is intuitive to think that it will do so best simply by presenting us with the sensory input from that world, free from our own interpretive biases, or even the biases encouraged by past exposure to that environment on previous occasions.

In this way, the purity norm is sometimes motivated by a further implicit psychological commitment, to the claim that this level of pure, sensory experience is importantly neutral, that is, it enjoys an independence even from past experience, let alone cognitive, theoretical commitments.

\footnotetext{
${ }^{7}$ Dretske's dispute with the sensory core described above is it that it is too narrow: he allows a far broader range of contents into the core. His (1981) distinction between sensation and perception is rich, and resists dismissal with the notion of the sensory core.
} 


\section{Purity Implication \#1}

Neutrality: there is some level of perceptual experience that is wholly insulated from theoretical commitments or past experiences.

Were something like Neutrality possible, there would be good reason to value it, epistemically. Such a level of perceptual experience could serve as an arbiter, (or provide the grounds for one), between individuals with differing environmental histories or theoretical commitments, allowing them to come to a common understanding of the world around them. It would thus be particularly wellplaced to serve as a corrective to flawed theoretical beliefs.

Borrowing Dretske's term, we could think of visual experience that satisfied the norms of Passivity, Purity, and Proximity as a kind of sensory core, a category of experience epistemically privileged in virtue of certain psychological characteristics. The sensory core is a level of perceptual experience epistemically valuable in virtue of psychological features, namely that it is received passively from the external world, pure of accretions of perceptual learning or extra-perceptual influence, and that consequently is as proximal as possible to retinal stimulation. ${ }^{8}$ Moreover, it gives rise to a natural ordering of experiences in terms of their distance and possible corruption from the sensory core. With further processing comes the potential for richer epistemic power, but also a possible reduction in it, as processing overwrites the sensory core that is simply given to us by the environment.

The influence of the notion of something like the sensory core extends well beyond foundationalist positions in perceptual epistemology. Consider, for instance, the debate around the epistemic impact of cognitive penetration. Cognitive penetration occurs when non-perceptual states such as beliefs, desires or intentions play a role in directly influencing the content of perceptual states. ${ }^{9}$ The literature in this debate challenges the exclusion of facts about the psychological history of a perceptual experience from the remit of the epistemologist. Problematic instances of cognitive penetration arguably seem capable of diminishing the epistemic power of an experience: if you see an object as a particular color only because you antecedently believe it to be that color, that visual

\footnotetext{
8 The notion of a sensory core has deep philosophical roots, in the distinction between sensation and perception, between a level of perceptual experience that is "devoid of active mental contributions - sensation" and a stage which is "...the result of the former stage and active mental contributions - perception" (Ben-Zeev 1984:327). On this distinction, it is sensation that puts us most immediately into contact with the world. Perception "makes something of" that basic perceptual data, and in doing so waters down its epistemic power. See Ben-Zeev (1984) for an interesting discussion of the historical roots of the alignment of passivity with the sensation side of the sensation / perception distinction. He also describes some of the ways that the passivity assumption has been associated with the notion of purity.

${ }^{9}$ It is a vexed question how exactly cognitive penetration should be defined (Silins 2016).
} 
experience cannot legitimately offer confirmation for the belief responsible for its contents. ${ }^{10}$ In her (2012), Susanna Siegel mobilizes the possibility of cognitive penetration to critique dogmatist approaches to perceptual justification, by eliciting the judgment that the particular subpersonal transformations that result in a given visual experience play a role in determining the extent of its capacity to justify belief. ${ }^{11}$

Despite Siegel's mobilization of cognitive penetration against dogmatist epistemology, in the debate over the epistemic significance of the phenomenon more broadly, we find all three of the norms described above in play. A norm of purity, and its association with neutrality, is in evidence in the debate between Jerry Fodor and Paul Churchland over whether perception is theory-laden, or informationally encapsulated (Churchland, 1979, 1988, Fodor 1984; 1988). Both Fodor and Churchland take informational encapsulation to have epistemic consequences via its impact on neutrality. Fodor in particular claims that encapsulated processes are more reliable in virtue of their independence from any elicit cognitive influence $(1984,1988)$. Fodor's argument is rooted in a conviction that purity and reliability will correlate with one another. ${ }^{12}$

For an instance of the influence of Proximity, consider Matthew McGrath, discussing the possibility of what he calls "freely enriched perceptual seemings" (that is, cognitively penetrated perceptual experiences of the kind discussed in Siegel (2012)) McGrath writes that "[s]uch seemings are experiences, but they are also part of what we make of the basic evidence, rather than parts of that basic evidence itself. Thus, they cannot provide foundational justification" (2013:237). Shortly afterwards he endorses a more general limitation: "I claim that quasi-inferential transitions between seemings function epistemically in the way inference by the person does: they can at best transmit the relevant epistemic property of the inputs to the outputs; they cannot generate this property for the outputs when it isn't possessed by the inputs" (2013: 237). Note that this principle assumes that subpersonal psychological transitions cannot enhance the value of an initial perceptual seeming, implying that that initial sensory impression is of maximal epistemic value. This example again exhibits how the literature on cognitive penetration, whilst moving away from the foundationalist position described above, nonetheless exhibits a commitment to norms of proximity and purity.

In fact, moving away from foundationalist epistemology of perception makes only more urgent the question of how we should evaluate the impact of perceptual processing on the epistemic power of experience. Towards the end of his argument in favor of a reliabilist solution to the

${ }^{10}$ For further discussion of the epistemic significance of color memory effects see Jenkin (ms). For more general discussion of the epistemic problems that cognitive penetration apparently gives rise too, see McGrath (2013), Silins (2016), Stokes (2012), Tucker (2014) among others.

${ }_{11}$ See too Siegel 2013, 2013(a), 2017.

${ }^{12}$ For another illustrative allusion to a purity norm, see Stokes' description of the concerns that cognitive penetration gives rise to in terms of infection: "If perception can be infected with background beliefs and other cognitive states, then the supposed epistemic role of perception is threatened." (2013:651) 
evaluation of the impact of cognitive penetration, Jack Lyons points the way forward by writing that "what matters is the mode of penetration, and in particular, whether the process is one that makes perception worse or better, where 'worse' and 'better' are truth-linked notions”' (Lyons 2011: 305). This focuses our attention on the question, what kinds of processes make perception better or worse? Similarly, Dustin Stokes writes that "the question then becomes, which kinds of influence are epistemically pernicious, and by what epistemic standards" (2013: 653). Once we allow that perceptual processing can impact epistemic power, we still stand in need of a framework for evaluating that impact.

Susanna Siegel in her (2017), broadens the discussion beyond cognitive penetration, to perceptual processing more generally. She argues that "both perceptual experiences and the processes by which they arise can be rational or irrational" (2017:15). Siegel claims that certain quasi-inferential moves that would in the case of belief be irrational, are similarly capable of downgrading the epistemic power of an experience (and that some such transitions are capable in turn of upgrading their epistemic power). Siegel proposes that we apply the standards of rational evaluation for belief to inferential transitions that result in perceptual states.

One reason to hesitate before endorsing this view is the obvious point that visual experience is not a form of belief. The question arises, what, then is it? What constitute appropriate norms for the evaluation of a process depend on the nature of the end result you are aiming for. Consider baking: you should start by creaming your butter and sugar together if you're making a cake, but not if you are making muffins. Similarly, our understanding of the impact of psychological processes on the epistemic "quality" of visual experience depends on what kind of a thing visual experience is. It is to this question that I turn in the next section, in the hope that doing so can guide us in the process of arriving at appropriate norms for the evaluation of perceptual processing.

\section{Visual experience as hypothesis}

What unites the norms of Passivity, Proximity and Purity is that they locate the item of maximal epistemic value at, or as close as possible to, the interface of sense organ and the world, by identifying it with retinal data, or sensory stimulation. This common presupposition contrasts with the dominant empirical model of visual perception. These "constructivist" models treat sensory stimulation itself as merely a partial input to a process that outputs the visual experience. On these models, the visual experience itself is akin to a hypothesis. An upshot of these models is that there is no stage of perceptual processing that has the psychological properties accorded to the sensory 
core. ${ }^{13}$ As a result, epistemic norms which give priority to such a level deliver either incoherent, or broadly skeptical results. We do better to treat the primary locus of epistemic power as the personlevel phenomenal experience (rather than the sensory signal), accommodating our epistemic norms to its dual status as both a kind of evidence (at the person level) and a form of hypothesis (viewed subpersonally).

What do I mean by a hypothesis? ${ }^{14}$ The process of scientific enquiry gives us a simple grasp on the distinction between hypotheses and data. Hypotheses are theories. They are interpretations of our data, that go beyond the information contained in it to draw further conclusions that are made probable, but rarely certain, by that data. Data spurs the development of hypotheses, and provides one measure against which they can be tested. Hypotheses in turn guide the search for further data. Crucial for our purposes is that a hypothesis is almost always underdetermined by the data that support it. ${ }^{15}$ A good hypothesis goes beyond the data. A good hypothesis does so by synthesizing data with other information.

The term "evidence" is epistemically laden: evidence designates information to which an individual is rationally bound to respond when forming her beliefs (Kelly 2008). At what stage of perceptual processing do we have something that is of evidential value to the individual? Minimalist norms imply that the sensory signal itself has this kind of status. This assumption grounds passive norms of perceptual processing: transmitting evidence is a passive process in the way that forming a hypothesis is not. ${ }^{16}$

Treating sensory signal as evidence for the individual becomes less plausible when we think of visual perception as a process of forming a hypothesis. A hypothesis can be evidence for an individual without the data that the hypothesis is itself grounded on being evidence for them. In this sense, the evidence relation is not transitive. Moreover, to form a successful hypothesis on the basis of a given body of data, you may have to do some violence to that body of data: cleaning it, disregarding certain points as noise, and combining it with other parameters that allow you to build up a coherent picture of how it meshes with what we already know about the world. Recognizing that visual experience - the locus of epistemic power - is akin to a hypothesis thereby licenses more

\footnotetext{
13 Note that this is consistent with their being a viable distinction at the experiential level between sensation and perception.

14 The term is sometimes used casually to indicate a mere conjecture, something as yet untested again the evidence, as when we say "but that's just a hypothesis". This is not the sense I am interested in here, as shall become apparent. I am interested in something closer to its use in scientific contexts, in which it is taken to have the characteristics here described.

15 I use data to refer to collected data that has not yet been cleaned. I use 'information' to refer to data that has been through a process of cleaning and evaluation, and that is consequently of some evidential value.

16 Gathering evidence by contrast may be an active process, possibly subject to rational norms.
} 
liberal epistemic norms for perceptual processing, norms that recognise the incompleteness of sensory signal, and the need to both supplement and clean it. ${ }^{17}$

The notion that visual experience is a kind of hypothesis is not new in vision science. It is often traced to Helmholtz's 1867 description of perception as an "inferential" process, integrating incoming information with prior expectations to arrive at a visual experience. ${ }^{18}$ That insight has given rise to "constructivist" models of visual perception, which have become the dominant paradigm in vision science. ${ }^{19}$ Constructivist models precisify the Helmholtzian insight that the visual system must infer the cause of retinal stimulation from an incomplete set of data. Constructivist models take a range of more specific forms: the particular processes by which the relevant reconstruction is effected is often modelled in Bayesian terms, or as a hierarchical predictive system. ${ }^{20}$ What matters for our current purposes is the commitment shared by different constructivist models, that visual experience represents a best guess on the part of the visual system, a kind of prediction of our external environment, informed and corrected by sparse retinal input which is incapable on its own of delivering a determinate representation of the distal stimuli that generate the experience in question. According to these models, our visual experience is merely the most likely interpretation of incoming retinal data in light of prior probability distributions.

These models take as their starting point the fact that the information the visual system receives via the retina directly from the external world underdetermines the distal stimulus. In this way, the visual system, in common with other perceptual systems, faces a "poverty of stimulus" challenge, which it must overcome in order to offer a rich and determinate representation of the external world. Brian Scholl succinctly describes the problem:

\footnotetext{
${ }^{17}$ On the approach I am taking, visual experience has a dual status: it is both a form of evidence, and a hypothesis, depending on the level of analysis: personal or subpersonal. This kind of dual status is not unusual. Frequently the fact that an entity produces a hypothesis may itself be a form of evidence for others. Consider a government that consists of multiple departments, which produce reports on their area of responsibility. Those reports have the status of a hypothesis for that particular department: the department (or its members) draw conclusions from a finite set of data via abductive inferences to arrive at a plausible, but ultimately uncertain, verdict. But for the government as a whole those reports serve as a kind of evidence. The fact the department of education has produced a report claiming that education is in a parlous state is evidence for the government that education is in a parlous state. Similarly, the fact the visual system has arrived at this representation is evidence for the individual that the environment is the way the experience represents it as being.

${ }^{18}$ Gary Hatfield traces the claim that perception involves unconscious inference back to Ptolemy in the $2^{\text {nd }}$ century AD and the $10^{\text {th }}$ century Arabic scholar Ibn Al Haythan (also known by the Anglicized name Alhazen, which Hatfield uses) via Descartes and Kant (Hatfield 2002).

${ }^{19}$ The term "constructivist" is used by Orlandi (2014) and Rescorla (2015).

${ }^{20}$ Bayesian models claim that new and old information is integrated in line with Bayes' theorem specifically (Feldman (2014), Rescorla (2015)). Predictive accounts place a greater emphasis on the role of top-down prediction in generating the visual experience, with the main role of bottom-up sensory signal being to serve as a corrective to the top-down predictive signal: see Clark (2013), Friston (2009) Hohwy (2013), or Vetter and Newen (2014).
} 
Visual perception is the process of recovering useful information about the structure of the world, based on the shifting patterns of light that enter the eyes. Perhaps the most fundamental fact about visual perception is that this task is, strictly speaking, impossible. That is, the shifting patterns of light that enter the eyes are insufficient by themselves to fix the structure of the external world from which that light was reflected or emitted (Marr, 1982) because there are always a multitude of possible structures in the world that could have given rise to those same patterns of light (2005:40-41).

Maria Olkkonen (2012) describes how the visual system finds itself facing this "impossible" task:

The first complication arises because the three-dimensional visual environment is projected on the two-dimensional retinal surface, confounding information about object, shape, size and distance. The second complication is due to the fact that various illuminant-reflectance combinations can produce the same light distribution, confounding information about light sources and surfaces. This projection of a three-dimensional world of objects illuminated by light sources to the surface of the retina means that there is no unique calculation from the retinal image back to the outside world. (2012:179)

The kind of ambiguity the visual system contends with in arriving at a representation of the scene before us is not restricted to size and distance, but extends to almost any visual property, including colour, shape, depth and motion. ${ }^{21}$ As a result "we experience vision as simple and easy, but in reality our brain has to work hard to create our visual experience from the light that enters the eye" (Olkonnen 2012:179).

Richard Gregory explicitly articulated the claim that visual experiences are not merely inferential, but can be understood by comparison with scientific hypotheses (Gregory, 1980). Constructivist models encourage this understanding. According to them, visual perceptual states can be viewed as attempts to explain the incoming retinal data by modelling 'how the world is' in the form of a visual representation of it. ${ }^{22}$

21 Olkonnen et al. 2012. Lotto (2002) provides a succinct summary of the "inherent ambiguity" of retinal stimulation. Clarke (2013) also includes a sustained discussion.

22 I have focused here on constructivist models of perception because of their dominance as a paradigm in contemporary vision science. The most salient alternatives are ecological models of visual perception.

Ecological models dispute both the claim that visual perception involves relevantly inferential processes, and the claim that the subpersonal states drawn on in those processes are representational (Orlandi 2014; 2016).

Ecological models of perception claim that the priors and inferences appealed to by constructivist models are better understood as interpretive biases, in consort with which the relevant incoming information determines a unique representation of the external world 
Three aspects of constructivist models are particularly important for our purposes, each of which will receive further elaboration in the discussion below. The first is that according to these models sensory signal invariably requires supplementation with non-retinal information. Retinal data is essentially incomplete, because there is a many-many relationship between retinal stimulation and the possible distal objects that cause it. The same pattern of light can be caused by a range of different objects in different lighting conditions. Similarly, the same object can cause various patterns of retinal stimulation, depending on the conditions under which it is viewed. The only way of narrowing that to a one-one relationship is by drawing on additional, non-retinal information. The second significant feature is that the priors on which the visual system draws (as part of the range of mechanisms by which it reduces that uncertainty) are importantly thought to be malleable. As I discuss below, the visual system learns from its past encounters via a range of high- and low-level mechanisms. The important upshot of that process is that the content of the resulting visual experience thus materially depends on features idiosyncratic to the particular individual, and their course through the world. Thirdly, it is worth noting that it is controversial whether and to what extent these priors are informationally encapsulated, or whether they can be influenced by extra-perceptual information. ${ }^{23}$ What is uncontroversial is that the direction of attention, and perceptual judgement are wholly

As a result, ecological models claim that constructivists place undue emphasis on the extent to which visual experience is underdetermined. That is in part because of the two approaches' different characterisations of the relevant stimulus. Constructivist accounts identify the stimulus in question with instantaneous incoming light received at the retina. Ecological models of perception, by contrast, draw attention to the way in which the individual receives this information within a particular, familiar environmental context to which they become attuned (Warren 2005:340). That process of attunement bolsters the incoming signal, so that simple retinal stimulation has a richer environmental significance for the individual, and is consequently capable of singling out a single determinate stimulus. The Ecologist also emphasises that the individual sees a scene or an object not for a single instant, but for a protracted period of time. This gives them the opportunity to view it from different angles, gathering an increasingly determinate set of retinal data in the process (Gibson 1979). Consequently, ecological models do allow that previously encountered information about the environment is incorporated into visual experience, but via a process of environmental adaption or attunement oriented towards facilitating effective action (Orlandi 2014, Warren 2012).

In an important way, then, ecological models of perception deny that visual experiences are appropriately understood as hypotheses, because they deny the underdetermination claim used to characterise hypotheses above. And yet they will agree with the Constructivist on the inability of retinal stimulation to privilege a representation of the environment, in the absence of environmentally-sensitive processing biases. In this respect, they are well-placed to endorse at least a substantial and important part of the claims I make below, and to resist norms of epistemic processing that place undue emphasis on the priority of retinal information, given their commitment to the importance of those biases and constraints, and their adaptability to novel environmental conditions.

${ }^{23}$ For arguments that claim that the early visual system is encapsulated, see Pylyshyn (1999), Firestone and Scholl (2016). By contrast, Clark (2013) and Lupyan (2015) both take predictive coding models of visual processing to imply systematic cognitive penetration. See MacPherson (2015) for critical push-back against Lupyan. 
penetrable, and the former, at least, has a significant impact on the content of the resulting visual experience. $^{24}$

\section{Hypotheses and minimalist norms}

In this section I draw out the ways in which treating visual experience as a kind of hypothesis is incompatible with the norms of Passivity, Purity and Proximity, and, consequently with the notion that there is a psychologically distinct level of experience that enjoys epistemic priority in virtue of its psychological proximity to raw, retinal stimulation. In so far as we take it as a given that visual experience does routinely justify belief, thereby allowing us to function effectively in our environment, this puts pressure on us to abandon those norms, and to overhaul our evaluation of perceptual processing in manner which does justice to the hypothesis-like nature of visual experience.

\subsection{Proximity...to what?}

Supposing we identify visual experience as a form of hypothesis that synthesises, but is not identical with, retinal data, in line with constructivist models of perception. This naturally gives rise to the following question: what is the epistemic significance of retinal data, the raw sensory stimulation on which the perceptual hypothesis is based?

Proximity implies that retinal data is of maximal epistemic value for the individual: proximity to it determines a kind of epistemic hierachy. But the under-determination problem described above gives us good reason to reject that claim. Though retinal data may play an important role in contributing to the hypothesis which constitutes the individual's perceptual experience, it should not itself be understood as a form of evidence for the individual, or as having epistemic priority over the resulting hypothesis. Retinal data lacks any determinate evidential valence, prior to perceptual processing. Far from obscuring or diluting the epistemic power of retinal data, perceptual processing is what creates the object of epistemic value, that is to say, the visual experience.

Most obviously, and flat-footedly, on both constructivist and ecological models, retinal stimulation taken on its own is experientially inaccessible at a person level, and that presents a prima facie barrier to its constituting perceptual evidence for the individual. The point isn't that retinal stimulation may on occasion be introspectively inaccessible, but that it is not even the kind of thing that could ever be directly accessed by the individual. ${ }^{25}$ On constructivist models, retinal data has to

\footnotetext{
${ }^{24}$ Firestone and Scholl (2016), for instance, attribute many of the visual effects purported to indicate penetration of the early visual module as instead attributable to influences on the inputs and outputs to that module, i.e. to influences on attention, and post-perceptual judgement.

25 Presumably, with the right technical apparatus, facts about an individual's retinal stimulation at a given moment could be accessed by them indirectly, via a process of scientific measurement and report. But this is not
} 
be combined with prior information that supplies other parameters required to construct an accessible interpretation of it. ${ }^{26}$ That process is not a matter of simply translating retinal stimulation into a format that is accessible to the person. The output of the process substantively depends on what other information is at the disposal of the visual system.

To see this, take the example of depth perception. Depth perception relies on a variety of retinal cues (Landy et al. 1995). Among these cues is the disparity between the binocular signals we receive. When you look at a box, the box produces a pattern of stimulation in one eye that is offset from the pattern it produces in the other. That disparity, coupled with an implicit value for the distance of the eyes from one another, lets the visual system derive a representation of the depth of objects before you. But the retinal information itself is representationally inert with respect to depth, until combined with that interpretive parameter. It isn't that the information is merely inaccessible, but that, taken on its own, mere sensory signal does not determine a particular depth. Retinal data about binocular distance is in effect a single input to a multivariable function that takes us from, for instance, values for the location of the eyes to a representation of depth. Taken on its own, it has no determinate evidential valence.

Similar points can be made for our perception of other, basic visual properties such as color or size. Only when it is integrated with parameters for lighting, surface texture and reflectance does retinal data determine a particular color percept. How large an object looks cannot be derived just from the size of the image on the retina. It requires a value for the distance of the object from the eye (Palmer 2002).

These points are significant for our understanding of how psychological processing impacts epistemic power for the following reasons: they focus our attention on the fact that the only personlevel epistemic good is a processed one. There is no unprocessed epistemic goodie that can serve as the initial supplier of epistemic power, and proximity to which could determine a kind of epistemic hierachy: processing is what gives rise to that epistemic goodie in the first place.

This puts pressure not just on Proximity but on Passivity too: the epistemic power of visual experience cannot depend on its passive reception from the environment, because no visual experience is passively received. This pressure compels us to specify more precisely what we mean by passivity. On one construal, a process is passive if it cannot alter the output, once the external input is specified. In this case, it merely transmits but does not transform information. By this standard, visual perception is not a passive process: it generates different outputs depending on the information the visual system brings to bear on the problem at hand. Moreover, these parameters are not simply

the sort of direct, immediate access taken to be epistemically foundational, and so is not capable of rendering retinal stimulation evidence of the relevant kind for the individual.

26 And according to ecological models, a set of environmentally-sensitive processing biases mediate between raw sensory stimulation and its accessible experiential form. 
innate. The visual system learns, adapting to its environment and the tasks it is called on to perform, in a way that changes the resulting person-level experience. ${ }^{27}$

An alternative construal of passivity focuses on the person-level. Jack Lyons, for instance, identifies a kind of passivity that arises from the modularity of perception. As he puts it "the outputs of perceptual processing are given, or receptive, in the sense that the perceiver is not agentially involved in their construction" (Lyons, 2016: 26). Facts about sub-personal processing leave this kind of person-level passivity untouched. No matter how wide the range of transformations the visual system can enact on retinal data, the individual has no control over that process. And this, so goes the thought, is what matters to the approach described by Sosa in section one above, on which the foundational epistemic power of experience flows from the way in which it is unmotivated by reason, and incapable, even, of manifesting obedience to rational norms.

Person-level Passivity runs into two major problems. The first is that many of the features that are supposed to render perception passive at the person level apply equally to belief, the go-to contrast case of a state that is not supposed to be person-level passive. In particular, there are good grounds for thinking that we do not have person level agency over our beliefs (Williams 1970; Hieronymi 2004, 2008). We are no more able to change our beliefs at will in the face of evidence than we can change our visual experience at will in the face of incoming sensory signal. Equally, we are frequently unaware and even incapable of accessing the inferential steps that get us from one belief to another, just as we are unaware of our perceptual processing. ${ }^{28}$ The second problem that faces Person-level Passivity is that many of the features that appear to make belief not passive apply equally to experience. The kind of indirect control we can exert over our beliefs through behaviors that determine what information we acquire is equally manifest in the perceptual case, where attention and gaze direction determine our visual experiences. Just as I can rerun a piece of reasoning when double-checking for flaws, so I can perceptually reappraise a particular object on demand. Perception and belief seem to be on a spectrum in this regard: on some occasions one can scrutinize and re-run the reasoning that led to the formation of a particular belief. In the perceptual case, by looking again, we can scrutinize and re-run only certain limited aspects of the perceptual process, and cannot directly assess or change the subpersonal inferences involved. ${ }^{29}$ But this is a difference of degree and varies case by case.

\footnotetext{
${ }^{27}$ Perceptual learning takes a wide range of forms, from short-term adaptation responses, to the long-term development of perceptual expertise. For a philosophical overview see Connolly (2017). For a detailed empirical overview, see Lu et al. (2011).

28 There is some evidence to suggest that what awareness we do have may frequently be the produce of posthoc confabulation (see for instance Kahan 2013).

${ }^{29}$ Consider, for instance, a case when I direct you to focus your attention in a particular way, allowing you to access an alternative visual interpretation of an ambiguous image or object.
} 
An alternative way of defending passivity insists that it retains some weight, even accepting that raw retinal data is inaccessible to the individual. It might not be possible for a visual experience to be entirely passively received from the environment, but it could still be the case that the less active processing a visual experience is subject to, and the more directly it subsequently reflects retinal stimulation, the greater the epistemic power of the resulting experience. We could call this norm, a norm that allows that no processing at all is not a coherent possibility, but that still insists that less is more, Comparative Passivity. ${ }^{30}$

Equally, the epistemic priority of retinal stimulation might seem to survive these observations. After all, though retinal data is inaccessible to the individual, it could still be the case that the epistemic power of person-level states is determined by their proximity to the retinal data. It remains possible that, as Quine would have, the order of causal proximity to sensory stimulation determines epistemic priority. An advocate of Comparative Proximity and Passivity could claim that we can draw substantive distinctions between different degrees of visual processing, and when we do so, those visual states that reflect retinal data with less interference are epistemically prior to those states that involve a greater degree of processing, or that are subsequently based on these more 'basic' visual experiences. ${ }^{31}$

The plausibility of a Comparative Proximity claim of this sort partly depends on the timeframe over which the relevant sensory stimulation is accrued. Over the lifetime of an organism it may be that the only information it receives directly from the environment is via the stimulation of the sensory receptors. In that sense, this information retains a certain priority. ${ }^{32}$ That diachronic priority claim comes apart from the claim that, at any given moment, the epistemic priority of an occurrent state depends on its proximity to the sensory receptors. Incoming data at a given moment may mislead or contain noise that is helpfully sifted out by interpretation in light of stored information gathered on previous occasions. Quine's claim is more plausible if that stored information too is identified as sensory stimulation. But at least in so far as Proximity makes a claim about the significance of occurrent sensory stimulation, we have reason to reject it.

\footnotetext{
${ }^{30}$ One difficulty with formulating Comparative Proximity lies in specifying the metric which provides the ordering of degrees of processing in this context given the incoherence of an entirely unprocessed visual experience that could serve as an ideal. Could such an ideal, whilst incoherent, nonetheless give rise to an ordering for a coherent norm?

${ }^{31}$ Fodor offers a justification of something like a form of comparative proximity in reliabilist terms when he observes that "observationally fixed beliefs tend, by and large, to be more reliable than inferentially fixed beliefs. This is primarily because the etiological route from the fact that $P$ to the belief that $P$ is metaphorically - and maybe literally - shorter in observation than in inference; less is likely to go wrong because there's less that can go wrong" (1984:24).

32 Even then, some aspects of the priors in light of which sensory signal is interpreted may be innate (Scholl 2005).
} 
Moreover, even a looser interpretation of the proximity claim sits poorly with the need for sensory stimulation to be supplemented with additional information, or interpreted in light of ecological biases. It is not the case that each time that happens the epistemic power of the initial sensory input is weakened: it may also be enhanced. As a result, the paralleling of proximity and epistemic priority is disrupted. A state later down the chain of processing, one that has, in effect, produced a greater return on the raw sensory data, could be taken as grounds for reappraising the significance of a state more proximal to the sensory stimulus. In the next section I flesh out that claim by considering the problem of noise in visual perception, and show how this is inconsistent with Comparative Proximity, and Passivity.

\subsection{Passivity and noise}

To better understand visual processing, we need to take a closer look at the way in which the visual system handles retinal noise. Doing so strengthens our grounds for rejecting a proximity norm. It also gives us reason to reject Passivity, the related Comparative Passivity, and their implication, that the function of visual processing is the mere transmission of the evidence provided by sensorystimulation. These norms preserve the thought that the visual system functions best when it transmits sensory signal as faithfully as possible. In particular, the visual system would seem to underperform if it ever overwrites or discards retinal information.

This intuition follows naturally from according epistemic value to retinal stimulation itself. If we think of sensory data as already constituting a form of evidence, then discarding it looks irrational. From the point of view of maximizing accuracy, more information seems obviously to trump less information. This line of thought suggests that the visual system goes astray if it ever discards sensory data. If that data conflicts with the hypothesis on which the visual system settles, and if retinal data is itself a form of evidence, then in disregarding it the individual seems to have ignored relevant counterevidence to the visual representation she takes as evidence..$^{33}$ Once we recognize that sensory data is not a form of evidence, at least not at the level of the individual, then we can begin to unknot this line of reasoning, and see that there can be cases when visual processing involves the disregard of retinal information without that rendering the resulting visual experience less capable of justifying belief. 34

\footnotetext{
33 This intuition can be equally readily justified in reliabilist terms. Assuming the eye is functioning properly then retinal signals are likely to track the state of the world. From this perspective, ignoring them is likely to generate less accurate visual experiences. The visual beliefs grounded on such experiences are likely to be less reliable than experiences which are sensitive to a greater quantity of sensory data.

34 This is a point at which norms for visual experience understood as a kind of hypothesis diverge from norms for belief, and hence from the norms Siegel (2017) proposes for perception. Since belief is not dealing with a problem of noise in quite the same way, the disregard of information may be appropriate for the visual system when it would be irrational in a parallel case of belief.
} 
Suppose that we identify visual evidence instead with a perceptual hypothesis that resolves the uncertainty in the sensory signal by integrating it with other, stored information. The question then becomes, does disregard of retinal data invariably impair the accuracy or reliability of the resulting hypothesis? The answer to this question is a clear negative. This argument proceeds in two steps. In the first place there are in-principle reasons to think that in certain situations, a hypothesis may be more accurate when it is based only on some part of the available data. Secondly, the hypotheses formed by the visual system are sometimes of just this kind.

A scientist analyzing data will not fit her curve to every data point. Doing so would prevent her from detecting significant trends, allowing her instead to be thrown off by outlying results that reflect errors in detection, rather than signal from the outside world. There are particular statistical methods designed to exclude outlying data that is likely to be noise. "Trimming", for instance, involves excluding some outlying percentage of a data set (say, 5\%). In a set with a perfectly normal distribution of variance, trimming decreases the accuracy of the mean. But as the distribution of variance diverges from a normal distribution, then the mean of a trimmed data set outperforms an untrimmed data set. Trimming functions then as an insurance policy against unreliability in the data. It is a "robust" statistical measure. In contexts in which robust statistical methods outperform nonrobust methods, data can be disregarded, in such a way that the data does not continue to count against the hypothesis in question (Huber 2011).

Disregarding certain data points as noise can itself be regarded as a form of response to that data. But it is a response in which the intuitive valence of those data points for or against a hypothesis (to the extent they can be said to have one at all) is suspended. Not every contrary data point gives rise to a form of counterevidence. Results that support too closely the hypothesis under consideration are often how scientific fraud is detected, when experimenters have interfered with or invented results that support their claims. In these cases, the concordance of the data with the hypothesis is in effect evidence against the hypothesis in question. The upshot is that we should expect data to be distributed such that certain data points, taken singly, are inconsistent with the hypothesis the body of data is ultimately taken to support.

Why think that the visual system in particular may produce more accurate hypotheses when it disregards certain data points? Sensory data is always noisy. Just like a scientist, the visual system has to tease apart noise from signal. Any successful interpretation of noisy data must neglect some of the apparent incoming information to avoid "overfitting" to the noise in the data. As Hohwy explains in the context of predictive models of visual perception, (2013: 41-46) overfitting increases prediction error, and thereby inaccuracy in perceptual representation of the environment. In screening-out that noise the visual system discounts certain pieces of sensory signal, but thereby increases the accuracy of its resulting predictions or representations. Dealing with noise is one very 
crude way in which the visual system can be described as insensitive to retinal information, whilst thereby increasing the accuracy of its representation of the external world. The visual system is not at fault when it produces a hypothesis that disregards some proportion of the sensory signal, nor is the individual in a weaker epistemic position when relying on a visual experience that is the result of such override.

There is evidence that, when faced with multiple conflicting retinal cues, the visual system does not simply average across them, but disregards certain cues on the basis of its assessment of their relative reliability in a particular context. Take again the example of depth perception, computed via a range of retinal cues. Landy et al. (1995) argue that the visual system maximizes accuracy of its depth perception by relying on robust methods, in light of the multiple cues that it must integrate, and that it discriminates between cues depending on their performance in a given context. For instance, a great deal of information about depth perception comes from stereoscopic information. And yet closing one of our eyes, and thereby restricting stereoscopic information, does not render the world suddenly flat as we might expect it to if the visual system continued to weight that information as it had been doing previously. ${ }^{35}$ Instead the visual system relies on information from lighting cues, its knowledge of the size and depth of objects, and parallax motion to generate a consistently 3D image.

This point has a direct analogue in Gerd Gigerenzer's work on heuristics. Gigerenzer criticizes the view, encouraged by, for instance, Amos Tversky and Daniel Kahneman (1973; 1974; Kahneman 2011) that there is an inevitable pay off between effort and accuracy, and that the use of heuristics minimizes the former at the cost of the latter. Gigerenzer argues by contrast that heuristics can in fact increase accuracy even as they ignore certain pieces of relevant information in certain contexts (Gigerenzer and Brighton 2009, Gigerenzer and Gaissmaier 2011). Gigerenzer and Gaissmaier call these "less is more" effects. ${ }^{36}$

This claim resonates with the issues under discussion here in a number of ways. In the first place, these effects provide a model for how the visual system might on some occasions ignore certain inputs in order to maximize representational accuracy. More broadly, we should heed the following point: cognitive heuristics and biases are often though to constitute flawed methods of belief formation, capable of rendering the resulting judgments unjustified, and of limiting their capacity to transmit justification. Whilst that may sometimes be the case, we move too quickly if we

35 Eric Schwitzgebel (2011) notes that Oliver Sacks (2006) and Brian O'Shaughnessy (2000) disagree with this claim. The former, now blind in one eye, claims to see the world as flat.

36 There may also be a tradeoff in these effects between accuracy at the level of more general patterns, or information about a set or kind, and accuracy concerning specific instances of that set. "Less is more" heuristics will tend to emphasize accuracy at the level of general trends over accuracy at the level of specific instances. The ecological value of the trade-off between these two will depend on the goals of the organism and the relative weight it gives to them. 
assume the inevitable illegitimacy of these processes and their results. This is just as true in the case of vision. Sometimes what looks like bias or insensitivity may be a legitimate process leading to the formation of accurate hypotheses. Even when cognitive biases involve the neglect of available sensory signal, they may improve the accuracy of the resulting judgments or inferences. In a similar manner, the functioning of the visual system may systematically incorporate 'bias' via its disregard of certain stimuli and reliance on prior information (in a manner that might resemble irrationality in the case of belief), without that providing a compelling reason to downgrade afflicted experiences.

The emerging upshot of this picture is that the function of the visual system is to do more than passively transmit information from the sense organ. Rather, the system must engage in some degree of sorting and evaluating of that data. The legitimacy of that process of filtering and disregarding information is at odds with the proximity norm. It allows that states further down the chain of processing, that is, less proximate to the sensory stimulus, can be used as the grounds to disregard retinal data. The plausibility of a given hypothesis concerning, say, depth, might give the visual system reason to disregard retinal data that is at odds with that hypothesis, though the latter is more proximal to the sensory receptors than the former. This counts equally against Passivity and Comparative Passivity: more processing - in the form of filtering and discard of possible data points does not equate to less epistemic power in the resulting experiences. And so, at the risk of a widespread perceptual scepticism, we should give up the claim that visual experiences enjoy epistemic power in virtue of their passive reception.

\subsection{Neutrality and attention}

These reasons for rejecting Passivity and Proximity give us cause to treat Purity too with suspicion. In section one, we saw how thinking of raw sensory signal as itself a form of evidence for the individual can lead us to think that visual perception is subject to a norm of purity.

Purity: visual experience is epistemically powerful in virtue of its purity from extra-sensory influence.

Purity is rooted in the intuition that retinal information is at its most accurate when it is as little adulterated as possible by other forms of information. Thinking of visual processing in terms of the passive transmission of retinal data encourages us to think that a set of such data is capable, by itself, of privileging a single determinate, maximally accurate neutral representation of the world.

If we think of visual experience as a hypothesis grounded on sensory data, purity does not describe a coherent norm for the visual system. Since sensory data is not the kind of thing that can be employed as evidence at the person level, the notion of an ideal, "pure" visual experience that directly reflects occurrent sensory stimulation with no influence from stored information or 
extrasensory processing constraints, is incoherent. In light of that, there is no straightforward ordering of visual experiences in terms of more or less "interference" with that data, with no interference as the relevant gold standard. Some non-retinal information must be drawn on in the process of generating a visual experience from the data in question.

Considering attentional effects will help to draw out the epistemic implications of this, and their incompatibility with Purity. ${ }^{37}$ Continuing the examples drawn from depth perception, we can take the case of a Necker cube (fig. 1). The Necker Cube is an ambiguous line drawing of a cube that can be seen with ether its lower left or upper right face protruding towards one. It is possible to manipulate which of the two one sees by altering where one focuses on the image. Attending to certain areas can make the image 'pop' from one interpretation to another.

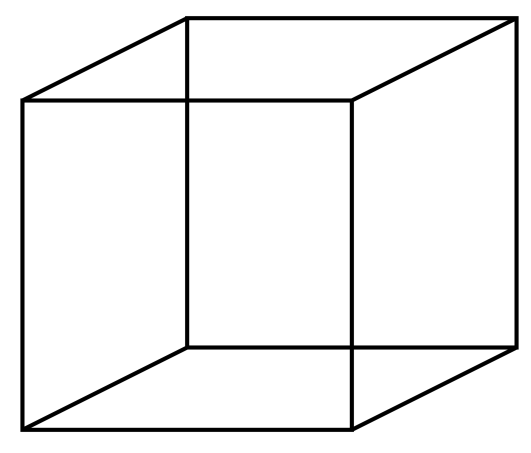

Figure 1: a Necker Cube

When looking at a Necker Cube, the visual system receives retinal data that is ambiguous between the two interpretations. Directing one's attention resolves that ambiguity. Two individuals who see different cubes when looking at the drawing may be able to redirect one another's attention so that they agree on the picture before them. But that will not help them privilege one or other interpretation of the image. What they see depends irreducibly on where they attend. The visual experience cannot be "cleansed" of that process: the direction of attention is a parameter which must be saturated for there to be an experience at all. ${ }^{38}$

Of course, the Necker Cube is an unusual example in so far as it concerns a deliberately ambiguous image. But that ambiguity allows it to offer a particularly clear instance of a more general phenomenon. In the case of the Necker Cube subjects can at least agree on the mark on the page

37 An added benefit of focusing on attentional effects is that doing so does not require us to posit any controversial penetration of an early visual module.

${ }^{38}$ It is arguably possible to look at a Necker Cube whilst avoiding determinately directing one's attention at it, to allow one to enjoy a kind of unsettled experience of it as just a $2 \mathrm{D}$ image on the page. But even this refusal to attend is rightly regarded as a possible value that the attentional parameter can take. 
which generate the ambiguous depth percept. In other cases, the direction of attention may affect even this low level of perception. An increasing body of research indicates that attention is not just an intensifying beam whose direction increases the accuracy of our perception of certain areas of our visual field, but that it is itself responsible for a range of visual effects that partly determine the contents of the resulting experience. Liverence and Scholl (2011) investigated the effect of sustained attention on perception of space. They conducted a series of experiments in which they presented subjects with an electronic display of four objects, asking them to attend to only two of them. Subjects were asked to report the position of the objects immediately after they disappeared. Surprisingly, where subjects attended affected their perception of the objects' spatial location. They perceived the targets of their attention as closer together than they really were, whereas inhibiting attention to the distractors expanded the perceived space between them.

Liverence and Scholl's result is unusual in finding that attention compresses rather than expands space, and in focusing on sustained rather than transient attention but it is certainly not isolated in suggesting that attention can determine the contents of visual experience. ${ }^{39}$ Carrasco, Ling and Reed (2004) had subjects compare the relative contrast of two striped patches. They found that attention increased the apparent contrast of the stimuli attended to: subjects estimated that patches to which they attended had a higher contrast than patches with the same contrast to which they were not directly attending. Andton-Erxleben, Henrich and Treue (2007) used a similar paradigm to investigate the effect of transient attention on the perceived size of stimuli, and found that attended stimuli appeared larger. Gobell and Carrasco (2005) applied the same paradigm to find that attention affected the appearance of spatial frequency and gap size, arguing that transient attention "not only affects basic visual processing - it changes what one experiences" (2005:644).

These are just a few examples from a growing family of results. Importantly, all these results problematize the claim that attention merely intensifies or focuses. They suggest it does more than that, that it can determine the very contents of experience. This in turn undermines the claim that sensory stimulation by itself privileges a unique representation of the external world. This does not mean we are prevented from accessing objects' veridical properties. Realistically, by distributing our attention over a scene in a range of different ways, and averaging the results we are likely to arrive at a reasonably accurate composite experience. Nonetheless, the point remains that we can never 'get back' to a pure, retinal experience cleansed of attentional effects, and the wide range of influences on them. Attention must be distributed in some way for there to be a visual experience at all.

In this respect, attention is just one instance of a general phenomenon: reliance on prior information of some kind or other is non-optional in the processes by which we arrive at a visual

\footnotetext{
39 See Beck and Schneider (2016) for dissent from this interpretation, and discussion of the results.
} 
experience. Purity of occurrent sensory data is not a coherent goal for the visual system, because there is no stage of perceptual experience that is independent of these kinds of influence. In light of that, Purity does not present a coherent norm. If the epistemic power of visual experience relied on its independence from extra-sensory influence, we would be forced to admit a widespread loss of epistemic power across the spectrum of visual experience, because no experience is free from extrasensory influence.

When we think of visual experience as a form of evidence this can seem counterintuitive. Evidence can, and often should, be kept pure from outside interference: think of a crime scene, cordoned off to protect the evidence from interference. Thinking of visual experience as a form of hypothesis loosens the grip of the purity norm upon us. Unlike evidence which benefits from isolation, hypotheses are often improved when they draw on more rather than less information. Constructivist models of visual experience suggest that we should think of it not so much as a crime scene, (which we could cordon off from outside influence), so much as the discussion between detectives over coffee and donuts (which benefits from information from a wide range of sources). This aspect of visual perception casts doubt too on the neutrality claim, described in section one. Since retinal data fails to deliver a conclusive verdict either way on how the world its, it does not, taken on its own, arbitrate neutrally or otherwise. Neutrality from theoretical commitments has been taken for granted as an epistemic goal for visual processing. That is thrown into doubt when we appreciate the ways in which the visual system relies on stored information, itself a form of theoretical commitment.

Fodor (1988) appears to raise an objection to this attack on Neutrality. Fodor accepts something like a constructivist model of perceptual processing, but he resists Churchland's claim that this threatens its neutrality. Fodor remains insistent that "perception is neutral, de facto, with respect to most of the scientific (and, for that matter, practical) disagreements that observation is called upon to resolve" (1989: 189, original emphasis). That is because perceptual processing "has access only to background information about certain pervasive features of the relationship between distal layouts and their proximal projections..." It is thereby "neutral with respect to almost all theoretical disputes" (1989:189). Fodor appeals to modularity as a means of defending the reliability of the visual system, a reliability which he ties to its neutrality.

In the first place, Fodor's defence in terms of modularity has little to say to the kind of attentional effects described above. The direction of attention is a process that uncontroversially occurs outside of the visual module. Influences upon it are not thereby subject to the kinds of restrictions Fodor takes comfort in: an antecedent belief that the Necker cube protrudes towards you can influence the direction of attention and thereby the resulting experience. But more significantly, the point at hand is not that rejection of Neutrality need induce any widespread crisis of confidence 
in the visual system. The objection is to the norm itself, and to the extent that Fodor's argument acknowledges some failure of neutrality whilst insisting nevertheless on the reliability of the perceptual system, this should encourage us to reappraise whether neutrality is a prerequisite for the epistemic power of experience. Accepting that influence by stored information is an inevitable part of perceptual processing should prompt us to find norms that accept and evaluate that influence, rather than starting from a position according to which influence per se is suspect. I turn now to considering one of the significant ramifications of this move away from a purity-based evaluation.

\subsection{Purity and bias in an uncertain world}

Even when we appreciate that the visual system relies on stored information of some kind or other, it can be hard to give up the intuition that Purity is an appropriate norm. One of the drivers of that intuition may be the worry that relying on prior information to tease apart how to weight and interpret retinal data leaves visual processing vulnerable to a kind of confirmation bias, in the sense that it selects evidence that fits the hypothesis it seeks to confirm, rather than collecting a neutral body of evidence equally capable on confirming or disconfirming the hypothesis of interest. Constructivist models of visual processing are compatible with a bias towards confirmation, but this feature of them need not be regarded an epistemic flaw, since it is capable of increasing the accuracy of the resultant visual experiences, and can be construed moreover as a rational response to the available information.

There are two stages at which a confirmatory pattern of evidence-gathering can seem to be built into constructivist models of visual processing. In the first place the visual system must tease apart genuine signal from noise in the data it receives. In the second place, the signal itself may be ambiguous, and require resolution in favour of one hypothesis or another. At both these stages the system relies on prior information. If the interpretation it settles on is capable of informing those same priors which contributed to its selection, then the system can, in effect, generate data that confirms the hypotheses that drive it.

Jona Vance calls this a 'feedback loop' (Vance 2014). Consider a simplified example: an observer looking at an object has to simultaneously resolve ambiguous retinal data about the size of the object and its distance from her. Suppose someone is looking at a camel. Relying on stored information about the likely size of camels, her visual system settles on a determinate interpretation of the object as at a given distance from her. Her visual experience of an average sized camel roughly fifty yards away may then strengthen her priors, visual or cognitive, concerning the average size of camels. In this way, the hypothesis that is itself under consideration (camels are yea large) intervenes to influence the evidence against which it will be tested (the size of this particular camel) in a manner redolent of a kind of pernicious confirmation bias. 
Bayesian interpretations of constructivism lets us see most clearly how a kind of confirmation bias may be built into the process of resolving uncertainty by appeal to prior information. Take the old example of a test for cancer. ${ }^{40} \mathrm{~A}$ woman in her forties should have a high prior that she does not have breast cancer - the chance she does is only 0.014. Suppose she has a mammogram that tests positive for cancer. What should she now believe? It might seem like she should straightforwardly believe she has cancer. But she first needs to bear in mind the probability of the mammogram being a false positive. Even if only one in ten positive mammograms are false positives, given the low prior probability that she has cancer, the chance that her test is a false positive is .9. That is, she should be $90 \%$ confident she does not have cancer, and that the test is a false positive. In this way, her high initial confidence guides her interpretation of new data in such a way that the data is interpreted in a manner that is consistent with her existing belief. But note that, whilst the datum of the positive mammogram does not sweep all before it, nor does it leave her prior confidence intact. After all, her confidence has fallen from being .986 to merely .9 that she does not have cancer. So some kind of confirmation bias in the immediate interpretation of a single datum is compatible with a longer-term incorporation of the information in question. Similarly, the visual system could disregard certain forms of incoming retinal information as likely to be noise in a particular instance, whilst still updating its priors to reflect the fact it encountered them.

A third, distinct kind of confirmation bias enters if the visual experience then goes on to influence belief states, which in turn inform the prior the visual system draws on when performing the interpretive tasks described above, leading to what Vance (2014) terms a kind of 'double counting. The evidence is counted once in the generation of the visual experience, and then again at the point when beliefs are based upon the visual experience. Siegel (2017) discusses similar examples, focusing on the way in which Bayesian models of perception allow background hypotheses about the likely shape or colour of an object to play a role in determining the percept one ultimately has of that stimulus. Siegel clams that any strengthening of confidence in the hypotheses which played a role in the determination of the experience on its basis is illicit (2017:117). This seems intuitive: if you only saw the banana as yellow in light of the high prior probability accorded to the possibility that bananas in general are yellow, it seems problematic if the resulting experience can directly shore up your confidence in that crucial general hypothesis, only for it to make still more probable further experiences that accord with it.

Vance offers several reasons to think that this kind of double counting may not in fact afflict perceptual processing that accords (to some extent at least) with Bayesian norms; in particular, it is likely that visual priors are encapsulated in a way that insulates them against reinforcement by visual

\footnotetext{
40 See Silver (2012) among many others, for discussion.
} 
belief. But we can in addition query the extent to which any of these patterns of processing need be regarded as pernicious. Whether or not these patterns of influence are epistemically pernicious depends on the role of the state that they influence. Evidence should be insulated from the hypothesis it tests, but hypotheses need not be insulated from one another.

Take again the scientist for comparison. When handling his evidence, the scientist should not simply interpolate or exclude results at will, guided by the hypothesis he aims to test. If he does so, he lays himself open to a vicious kind of circularity that insulates him from the potential falsifying force of his evidence. When generating a hypothesis on the other hand he can appropriately draw on his prior beliefs and expectations, including other hypotheses. This inevitably gives rise to a kind of confirmation bias: he selects hypotheses that cohere with and support the hypotheses he already holds. This kind of confirmation bias is a result of the fact that scientific enquiry is sensitive to the value of coherence between different theories.

Coherence is a legitimate epistemic virtue amongst hypotheses. The inevitable underdetermination of hypotheses by evidence compels reliance on other measures in their selection and evaluation. The epistemic value of evidence, on the other hand, is determinate. Skewing or selecting evidence to improve its fit with a hypothesis inevitably results in a loss of potentially valuable information. ${ }^{41}$ Valuing coherence among hypotheses inevitably gives rises to a kind of weak confirmation bias: we favour hypotheses that fit with the hypotheses we already endorse. The good fit of those novel hypotheses further supports the hypotheses against which we measured them. By extension, favouring visual representations that cohere with our other representations of the world may constitute the pursuit of an epistemic virtue, and result in visual experiences that are, by and large, more accurate.

To put this in the context of visual perception: Bayesian perceptual processing theoretically allows some degree of circularity, if the resulting visual experience or belief can flow back to influence the distribution of prior probabilities that contributed to its determination. But on another way of looking at this, the prior that the experience supports, (say, that bananas are yellow) has undergone a relevant test (the examination of another banana). We can think of the visual experience as a kind of gatekeeper: it lets through surprising verdicts if and only if the data that supports them is strong enough to overcome the prior probabilities that count against those results. The system is open enough to conflicting data that the sustenance of the hypothesis in light of this further test constitutes relevant new information in light of which increased confidence in the prior may be legitimate. Part of that relevant new information is the fit between this visual experience, understood

41 Of course, the value of this coherence is contingent on the quality of the other hypotheses with which the hypothesis in question is made to cohere. The extensive debate over the relationship between coherence and truth-conduciveness is relevant here. See Olsson (2005) for criticism of claims by, among others, Bonjour (1985), and C.I. Lewis (1946) that coherence is truth-conducive. 
as a kind of hypothesis designed to account for the novel data, and the prior distribution of probabilities over a set of hypotheses that contributed to its generation. Proper sensitivity to the occurrent stimulus is compatible with some degree of confirmation bias, in the form of resistance to highly surprising data, that makes it harder for that data to heavily influence the resulting hypothesis.

This point can seem counterintuitive because the dual status of visual experience, as evidence and hypothesis, gives rise to conflicting epistemic evaluations. Viewed as a kind of evidence, there are reasons to think that visual experience is likely to be most epistemically valuable when it is insulated from influence by the belief-hypotheses under consideration. Viewed itself as a kind of hypothesis formed on the basis of retinal data, one generated by a system struggling with challenges of under-determination, visual experience is likely to be most accurate when it is sensitive to the content of certain other perceptual or even cognitive hypotheses.

In theory-testing more generally, and in the visual system, we arrive at the most accurate hypotheses when we have the correct balance of bottom-up sensitivity and top-down guidance. ${ }^{42}$ Where that balance lies is an empirical question that depends on factors external to the individual, including the rate of change in their environment, for instance. (As the rate of change increases, giving greater weight to bottom-up signals is likely to increase accuracy).

\section{Conclusion}

Appreciating the ways in which visual experience is best understood as a kind of hypothesis offers us powerful resources for reappraising the epistemic norms we apply to the psychological processes that underlie it. In particular, understanding it as a hypothesis is at odds with norms that treat sensory stimulation, such as retinal data, as the ultimate source of epistemic value. That entails the rejection of a web of associated norms: that proximity to retinal stimulation corresponds with epistemic power, and that visual processing is essentially passive, oriented towards preserving the purity of the retinal data. These norms are unsustainable in light of empirical models of the way in which such data underdetermines visual experience, requiring supplementation with stored information or interpretive biases.

Moving forwards, these considerations point us away from decrying cognitive influence on perception per se. Sensory receptors are not direct windows onto the world. They gather uncertain information which is always subject to interpretation in light of stored information of some kind or other. Accepting this positions us to distinguish between positive and negative instances of cognitive influence or penetration, by helping us to understand their actual impact on accuracy and reliability.

\footnotetext{
42 Brewer and Lambert (2001).
} 
We need to ask, then, what features of perceptual processing are likely to enhance the accuracy with which visual experiences represent the environment, when we understand those visual experiences as a kind of hypothesis? What kinds of influence, and what forms of stored information, will allow the visual system to form representations that track the state of the world? Plausibly, information that itself tracks the state of the external world is more likely to facilitate perceptual representations that do so. This could give us some grounds for still thinking perceptual modularity would be epistemically advantageous. The content of information stored within the visual system is more likely to accurately track the external world, since it is restricted to information that has been gathered in the past from that world. Equally, the information most likely to survive as a prior is that which results from repeated viewing of a particular stimulus. Within-module influence is in effect harder to 'hack' with non-veridical information.

But even this general rule needs considerable further nuance: in particular, extra-modular impact will be of greater benefit in fast-changing environments, when beliefs can update more quickly than priors stored within a module. Additionally, the underdetermination problem more generally gives us reason to reappraise our suspicion of extra-modular influence, and the claim that it would reduce reliability. There may be instances when such influence has the potential to enhance the accuracy of visual experience, in addition to occasions on which it detracts from it.

\section{Bibliography}

Anton-Erxleben, K., Henrich, C., \& Treue, S. (2007). "Attention changes the perceived size of moving visual patterns." Journal of Vision, 7 (11).

Austin, J. L. (1962). Sense and Sensibilia. Oxford University Press.

Beck, J. \& Schneider, K. (2016). Attention and Mental Primer. Mind and Language.

Ben-Zeev, A. (1984). The passivity assumption of the sensation-perception distinction. British Journal for the Philosophy of Science 35 (December):327-343.

BonJour, L. (1985). The Structure of Empirical Knowledge. Harvard University Press.

Brewer, W. \& Lambert, B. L. (2001). The theory-ladenness of observation and the theory-ladenness of the rest of the scientific process. Philosophy of Science 3 (September):S176-S186.

Carrasco, M., Ling, S., \& Read, S. (2004). Attention alters appearance. Nature neuroscience, 7(3), 308313.

Churchland, P. M. (1979). Scientific Realism and the Plasticity of Mind. Cambridge University Press. 
Churchland, P. M. (1988). Perceptual plasticity and theoretical neutrality: A reply to Jerry Fodor. Philosophy of Science 55 (June):167-87.

Clark, A. (2013). Whatever next? Predictive brains, situated agents, and the future of cognitive science. Behavioral and Brain Sciences, 36(3), 181-204.

Connolly, K., (2016) "Perceptual Learning", The Stanford Encyclopedia of Philosophy (Summer 2017 Edition), Edward N. Zalta (ed.)

Dretske, F. (1969). Seeing And Knowing. Chicago: University Of Chicago Press.

Dretske, F. (1981). Knowledge and the Flow of Information. MIT Press.

Feldman, J. 2014. Bayesian Models of Perceptual Organization in J. Wagemans (ed.) Oxford Handbook of Perceptual Organization. Oxford, OUP.

Fireston, C. and Scholl, B. (2016) Cognition does not affect perception: Evaluating the evidence for "top-down" effects Behavioral and Brain Sciences 39 e229 1-77

Fodor, J. (1988). A reply to Churchland's 'perceptual plasticity and theoretical neutrality'. Philosophy of Science 55 (June):188-98.

Fodor, J. A. (1984). Observation reconsidered. Philosophy of Science 51:23-43.

Friston, K. (2009). The free-energy principle: a rough guide to the brain? Trends in Cognitive Sciences, 13(7), 293-301.

Gigerenzer, G. and Brighton, H. (2009). Homo Heuristicus: Why Biased Minds Make Better Inferences Topics in Cognitive Science 1:107-143

Gigerenzer, G. and Gaissmaier, W. (2011). “Heuristic Decision Making”. Annu, Rev. Psychol. 62:451-82

Gobell, J., \& Carrasco, M. (2005). "Attention alters the appearance of spatial frequency and gap size." Psychological Science, 16, 644-651.

Gregory, R. L. (1980). Perceptions as Hypotheses. Philosophical Transactions of the Royal Society of London. Series B, Biological Sciences, 290(1038), 181-197.

Harman, G. (1973). Thought. Princeton University Press.

Hatfield, G. (2002). Perception as Unconscious Inference. In Dieter Heyer \& Rainer Mausfeld (eds.), Perception and the Physical World: Psychological and Philosophical Issues in Perception. 113-143.

Helmholtz, H. Von (1867) Treatise on Physiological Optic III The Optical Society of America 1925.

Hieronymi, Pamela (2008). Responsibility for believing. Synthese 161 (3):357-373.

Hieronymi, Pamela (2004). The force and fairness of blame. Philosophical Perspectives 18 (1):115-148.

Hohwy, J. (2013). The Predictive Mind: Oxford University Press.

Huber, P. J. (2011). Robust statistics. In International Encyclopedia of Statistical Science (pp. 1248-1251). Springer Berlin Heidelberg. 
Huemer, M. (2001). Skepticism and the Veil of Perception. Lanham: Rowman \& Littlefield.

Huemer, M. (2007). Compassionate phenomenal conservatism. Philosophy and Phenomenological Research 74 (1):30-55.

Huemer, M. (2013). "Epistemological Asymmetries between Belief and Experience." Philosophical Studies.162 741-748

Kahan, D. M. (2013). Ideology, motivated reasoning, and cognitive reflection. Judgment and Decision Making, 8, 407-424.

Kahneman, D. (2011). Thinking, Fast and Slow. New York, NY: Farrar, Straus \& Giroux

Kelly, T. (2008). Evidence: Fundamental concepts and the phenomenal conception. Philosophy Compass, 3(5), 933-955.

Landy, M. S., Maloney, L. T., Johnston, E. B., \& Young, M. (1995). Measurement and modeling of depth cue combination: in defense of weak fusion. Vision research, 35(3), 389-412.

Lewis, C. I., 1946, An Analysis of Knowledge and Valuation, LaSalle: Open Court.

Liverence, B. and Scholl, B. (2011). "Selective Attention Warps Spatial Representation: Parallel but Opposing Effects on Attended vs. Inhibited Objects” Psychological Sciences 22.12 1600-1608

Lotto, B. R. (2002). The empirical basis of color perception. Consciousness and Cognition, 11(4), 609-629.

Lupyan, G. (2015) Cognitive Penetrability of Perception in the Age of Prediction: Predictive Systems and Penetrable Systems. Review of Philosophy and Psychology 6.4: 547-569

Lu, Z. L., Hua, T., Huang, C. B., Zhou, Y., \& Dosher, B. A. (2011). Visual perceptual learning. Neurobiology of learning and memory, 95(2), 145-151.

Lyons, J. (2011). Circularity, reliability, and the cognitive penetrability of perception. Philosophical Issues, 21(1), 289-311.

Lyons, Jack C. (2016). Inferentialism and cognitive penetration of perception. Episteme 13 (1):1-28.

Lyons, J. (2016a). Experiential evidence? Philosopbical Studies 173 (4):1053-1079.

Macpherson, F. (2015) Cognitive Penetration and Predictive Coding: A Commentary on Lupyan Review of Philosophy and Psychology 6.4: 571-584

McGrath, Matthew. (2016). Looks and perceptual justification. Philosophy and Phenomenological Research. 94 (3)

O'Shaughnessy, Brian (2000). Consciousness and the World. Oxford University Press UK.

Olkkonen, M., Hansen, T. \& Gegenfurtner, K.R. . (2012). High-level perceptual influences on color appearance. In G. A. Hatfield, S. R. (Ed.), Visual Experience: sensation, Cognition and Constancy (pp. 178-198). Oxford: Oxford University Press.

Olsson, E. (2005). Against Coberence: Truth, Probability, and Justification. Oxford University Press.

Orlandi, N. (2014). The Innocent Eye: Why Vision is Not a Cognitive Process. OUP. 
Orlandi, N. (2016). Bayesian perception is ecological perception. Philosophical Topics 44.2

Palmer, S. E. (2002). Perceptual organization in vision. Stevens' handbook of experimental psychology.

Pryor, J. (2000). The Skeptic and the Dogmatist. Nous 34.4 517-549

Pryor, J. (2005). There is immediate justification. In Matthias Steup \& Ernest Sosa (eds.), Contemporary Debates in Epistemology. Blackwell 181--202.

Pylyshyn, Z. (1999) Is vision continuous with cognition? Behavioral and Brain Sciences 22: 341-365

Quine, W. V. (1969). Epistemology Naturalized. In Ontological Relativity and Other Essays. New York: Columbia University Press

Rescorla, M. 2015. Bayesian Perceptual Psychology. In M. Matthen (ed.) The Oxford Handbook of Philosophy of Perception OUP.

Russell, B. (1921). The Analysis of Mind. Duke University Press.

Silver, N. (2012). The signal and the noise: why so many predictions fail--but some don't. Penguin.

Sacks, O. (2006). Stereot Sue. Ner Yorker, June 19: 64-73

Scholl, B. J. 2005. Innateness and (Bayesian) visual perception: Reconciling nativism and development. In P. Carruthers, S. Laurence, \& S. Stich (Eds.), The structure of the innate mind. Cambridge: Cambridge University Press.

Schwitzgebel, Eric (2011). Perplexities of Consciousness. Bradford.

Siegel, S. (2012). Cognitive Penetrability and Perceptual Justification. Noûs, 46(2), 201-222.

Siegel, S. (2013). Can Selection Effects on Experience Influence its Rational Role? In T. Gendler (Ed.), Oxford Studies in Epistemology volume 4 (pp. 240): Oxford.

Siegel, S. (2013a). The epistemic impact of the etiology of experience. Philosophical Studies, 162(3), 697722.

Siegel, S. 2017. The Rationality of Perception.

Silins, Nicholas (2016). Cognitive Penetration and the Epistemology of Perception. Philosophy Compass 11 (1):24-42.

Silver, N. (2012). The Signal and the Noise: Why So Many Predictions Fail-But Some Don't. Penguin. Sosa, E. (2007). A Virtue Epistemology. Oxford University Press.

Stokes, Dustin (2012). Perceiving and Desiring: A New Look at the Cognitive Penetrability of Experience. Philosophical Studies 158 (3):479-92.

Stokes, D. (2013). Cognitive Penetrability of Perception. Philosophy Compass.663 646:(7) 8

Tucker, C. (2014). If Dogmatists Have a Problem with Cognitive Penetration, You Do Too. Dialectica 68 (1):35-62.

Tversky, A., \& Kahneman, D. (1973). Availability: A heuristic for judging frequency and probability. Cognitive psychology, 5(2), 207-232. 
Tversky, A., \& Kahneman, D. (1974). Heuristics and biases: Judgement under uncertainty. Science, 185, 1124-1130.

Vance, J. (2014). Cognitive Penetration and the Tribunal of Experience. Review of Philosophy and Psychology, 6(4), 641-663.

Vetter, P., \& Newen, A. (2014). Varieties of cognitive penetration in visual perception. Conscious Cogn, 27, 62-75.

Warren, W.H. (2005). Direct perception: The View from here. Philosophical Topics 33.1: 335-361

Warren, W.H. (2012). Does this computational theory solve the right problem? Marr Gibson, and the goal of vision. perception 41.9 1053-1060

Williams, B. (1970). Deciding to believe. In Bernard Williams (ed.), Problems of the Self. Cambridge University Press. pp. 136--51.

Williamson, T. (2000). Knowledge and Its Limits. Oxford. OUP. 